\title{
Siliceous spicules of Tethya seychellensis (Porifera) support the growth of a green alga: a possible light conducting system
}

\author{
Elda Gaino, Michele Sarà \\ Institute of Zoology, University of Genova, Via Balbi 5, I-16126 Genova, Italy
}

\begin{abstract}
In Tethya seychellensis (Wright), a demosponge collected on the coral reef of the Maldive Islands, algal filaments of the syphonaceous chlorophyte Ostreobium sp. were seen to penetrate deep into the sponge body. The filaments were in close association with the sponge skeleton, which consists of siliceous spicules. Filaments were arranged around the spicular bundles radiating from the central core of the sponge body into the outermost cortical region. In sponges like Tethya, which is characterized by a massive globular shape and radial structure, spicular tracts may represent a system to entrap and guide light toward the center of the sponge body. In such conditions, algal filaments develop in an environment otherwise prohibitive for autotrophic organisms. These data suggest that sponges could use spicules as a natural pipeline for light, a natural condition similar to modern fibre-optic systems.
\end{abstract}

KEY WORDS: Green algae $\cdot$ Sponges - Optical fibres Symbiosis

\section{INTRODUCTION}

Sponges show a wide repertoire of associations with bacteria and photosynthetic organisms, such as zooxanthellae, zoochlorellae, and mono- or multicellular cyanobacteria (Sarà \& Vacelet 1973, Wilkinson 1980, Simpson 1984, Larkum et al. 1987). Whereas bacteria are widespread in the sponge body, photosynthetic organisms only grow under suitable conditions of illumination. This fact represents a constraining factor in their pattern of distribution, for photosynthetic organisms are relegated to the superficial layer of the sponge body.

The association of algal filaments with the sponge body has occasionally been observed. Rhodophyta may reside within skeletal fibres (Sarà 1966), which they may substitute or reinforce. Spongin is sometimes deposited around the algal wall and may totally engulf it (Rutzler 1990).

Algal filaments attributed to the chlorophyte Ostreobium cf. constrictum have been described within the skeletal fibres of Mycale laxissima, a sponge with a loose body texture (Rützler 1990) that does not impair light penetration.

We observed a peculiar association between the spicular bundles of the massive demosponge Tethya seychellensis (Wright) and a filamentous green alga belonging to Ostreobium sp.

\section{MATERIAL AND METHODS}

Tethya seychellensis was detached from its substratum (after the removal of a covering of $50 \mathrm{~cm}$ of reef debris) at $3 \mathrm{~m}$ depth in the lagoon of Ari Atoll, the Maldive Islands, and was preserved in $3.5 \%$ formaldehyde in artificial seawater.

For scanning electron microscopy investigation, fragments of the sponge body were dehydrated in a graded series of ethanol and critical-point dried with a $\mathrm{CO}_{2}$ Pabish CPD 750 apparatus. Thereafter specimens were mounted on stubs, coated with gold in a Balzer Union Evaporator and observed with a Philips 515 electron microscope. 


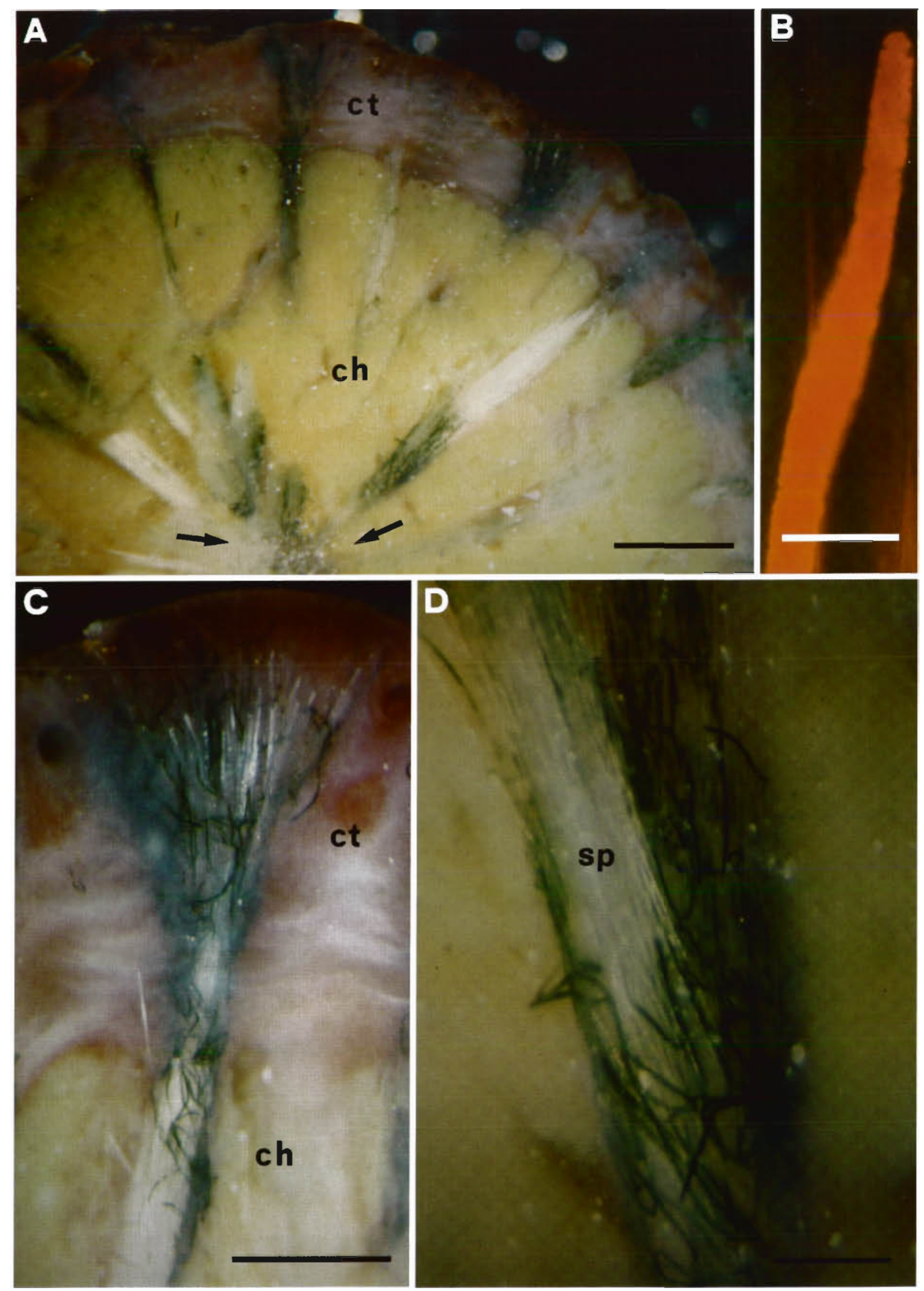




\section{RESULTS}

Like all other species of the genus, Tethya seychellensis presents a spheroidal shape. Coronal sections through the core of the sponge body reveal a well demarcated, 2 to $3 \mathrm{~mm}$ cortical region and an inner choanosome that forms the larger portion of the massive sponge body (Fig. 1A). The green algal filaments are entangled around the sponge skeletal network (Fig. 1A, D), and extend from the outermost surface into the sponge core (Fig. 1A, C).

Natural fluorescence shows that the algal thallus has no constrictions, a feature consistent with its coenocytic organization (Fig. 1B), suggesting that this Chlorophyta should be included in the Syphonales order, genus Ostreobium (Bornet \& Flahault 1889).

The sponge has a radial spicular skeleton consisting of siliceous megascleres arranged in bundles about $450 \mu \mathrm{m}$ across, arising from the central core of the sponge body. Spicules are of the strongyloxea type, rounded at the base and tapering distally. They measure 25 to $30 \mu \mathrm{m}$ in diameter and 1200 to $1300 \mu \mathrm{m}$ in length. Each bundle is made up of multiple, longitudinally overlapping spicules. The radiating tracts fan into the cortical region to form spicular brushes (Fig. 1C), which sprout slightly through the sponge surface. The distance from the outermost surface to the sponge core is about $12 \mathrm{~mm}$, a span that could be theoretically covered by 10 spicules. However, a few more spicules are present because of their partially overlapping arrangement.

The algae, thallus of about $20 \mu \mathrm{m}$ in diameter, are attached to each radiating tract. They can be easily discerned as bright green filaments (Fig. 1D). No other part of the sponge body is attained by the alga, which only develops in close association with the spicule bundles (Fig. 2).

\section{DISCUSSION}

Ostreobium spp. inhabit the skeletons of both brain coral (Jeffry 1968) and reef coral (Lukas 1974), and are considered chlorophytes adapted to dim light. Indeed, an analysis on the light penetrating the coral
Favia pallida and reaching the layer of algal filaments indicated that only light at wavelengths $>680 \mathrm{~nm}$ contributed to the illumination of the alga (Shibata \& Haxo 1969). The growth of Ostreobium sp. exclusively along the spicules goes beyond any adaptation to extreme environmental condition and supports the view that siliceous bundles could receive some light from the outside. Various tridacnid clams use hyaline organs' for concentrating light into the deeper part of the animal tissues associated with zooxanthellae (Yonge 1936). In contrast, Ostreobium cf, constrictum grows within the spongin fibers in Mycale laxissima with no particular arrangement (Rützler 1990). We speculate that the loose texture of the body structure of this species could allow light to penetrate throughout the sponge tissues.

We postulate that the skeleton of radiate siliceous spicules of Tethya seychellensis could constitute a system for conducting light energy from the outside into the core of the sponge body. This hypothesis is supported by the observation that algal filaments live only in close association with the spicules along the cortical brushes and along the more densely packed bundles of the innermost choanosome. In addition, algal filaments do not spread into the rest of the sponge tissue. Furthermore, their peculiar adhesion to the spicules suggests that the spicules determine the only favourable site for algal photosynthesis within the sponge body. Spicule bundles could be regarded as a natural light conductor, similar to fibre-optic systems, light-guiding paths with minimal absorption.

In the tropical coral reef environment, sponges from photic zones act like autotrophic organisms owing to their associations with photosynthetic cyanobacteria (Wilkinson 1980). The colonization of the siliceous skeleton of the sponge by green algae represents a new strategy that allows autotrophic processes even in the deeper body regions. In addition, Ostreobium sp. may transfer nutrients to the sponge, thereby constituting a metabolic source for Tethya seychellensis, as evidenced by other associations between sponges and microorganisms (Sarà 1971, Wilkinson 1979, 1980. Rützler 1981).

In conclusion, we suggest the hypothesis that light energy reaches the innermost part of the sponge body

Fig. 1. Ostreobium sp. associated with Tethya seychellensis. Green algal filaments of the syphonaceous chlorophyte Ostreobium sp. are associated with the siliceous spicules of the sponge. (A) Coronal section showing the organization of the sponge body, including choanosomal region (ch) and overlying cortex (ct). Green algal filaments are tangled with radially arranged spicular bundles. The bundles originate from the sponge core (arrows) and extend into the cortex (scale bar $=2.5 \mathrm{~mm}$ ). ( $\mathrm{B}$ ) A segment of an algal filament with natural fluorescence revealing the lack of septa along the thallus (scale bar $=50 \mu \mathrm{m}$ ). (C) Spicular bundles radiating from the choanosomal region (ch) in the sponge core and brushing into the cortical region (ct). Note the green algal filaments that grow in association with spicules (scale bar $=1 \mathrm{~mm}$ ). (D) Detail of a spicular bundle at its origin in the sponge core. Note the contrast between green algal filaments and white siliceous spicules (sp) (scale bar $=400 \mu \mathrm{m}$ ) 


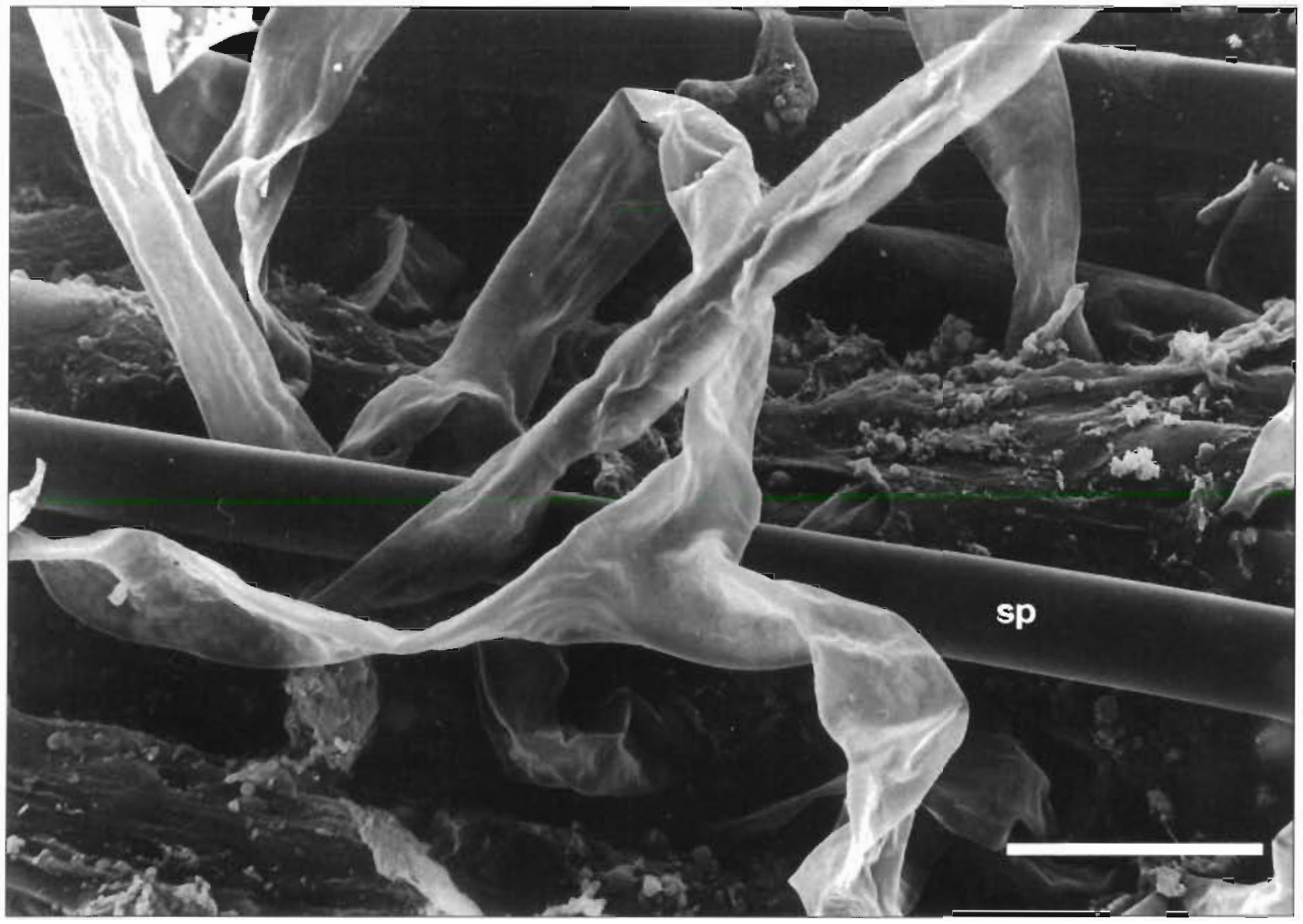

Fig. 2. Tethya seychellensis. Scanning electron micrograph showing the shape of the green algal filaments of Ostreobium sp. growing along the siliceous spicules (sp) of the sponge. Filaments enveloping spicules were experimentally pinched off to show their morphology (scale bar $=50 \mu \mathrm{m})$

via siliceous spicules, influences several aspects of sponge biology (Rasmont 1970) and triggers the onset of oogenesis (Elvin 1976).

Direct measurements of light penetration inside the sponge body in response to specific lighting conditions could support our hypotheses with quantitative data.

Acknowledgements. We thank Dr P. Modenesi for his help in the identification of the algal filaments and Dr C. Pesce for his suggestions and criticism. This work was supported by the Italian funds from the Italian M.U.R.S.T.

\section{LITERATURE CITED}

Bornet, E., Flahault, C. (1889). Sur quelques plantes vivant dans le test calcaire des mollusques. Bull. Soc Bot. 36: $147-176$

Elvin, D. W. (1976). Seasonal growth and reproduction of an intertidal sponge, Haliclona permollss (Bowerbank). Biol. Bull. 151: 108-125

Jeffry, S. W. (1968). Pigment composition of Siphonales algae in the brain coral Favia. Biol. Bujl. 135: 141-148

Larkum, A. W. D., Cox, G. C., Hiller, R. G., Parry, D. L., Dibbayawan, T P. (1987). Filamentous cyanophytes contain- ing phycourobilin and in symbiosis with sponges and an ascidian of coral reef. Mar. Biol. 95: 1-3

Lukas, K. J. (1974). Two species of chlorophyte genus Ostreobium from skeletons of Atlantic and Caribbean reef corals. J. Phycol. 10: 331-335

Rasmont, R. (1970). Some new aspects of the physiology of fresh-water sponges. In: Fry, W. G. (ed.) The biology of Porifera, Symp. Zool. Soc. London. Academic Press, New York, p. 415-422

Rützler, K. (1981). An unusual bluegreen alga symbiotic with two new species of Ulosa (Porifera: Hymeniacidonidae) from Carrie Bow Cay, Belize. P.S.Z.N. I: Mar. Ecol. 2: $35-50$

Rutzler, K. (1990). Associations between Caribbean sponges and photosynthetic organisms. In: Rützler, K. (ed.) New perspectives in sponge biology. Smithsonian Institution Press, Washington, DC, p. 455-466

Sarà, M. (1966). Associazioni tra Poriferi e alghe in acque superficiall del litorale marino. Ric. Sci. 36: 277-282

Sarà, M. (1971). Ultrastructural aspects of the symbiosis between two species of the genus Aphanocapsa (Cyanophyceae) and Ircinia variabilis (Demospongiae). Mar. Biol. 11: $214-221$

Sarà, M. Vacelet, J. (1973). Ecologie des démosponges. In: Grassé, P. P. (ed.) Traité de Zoologie, Vol. III, Fasc. 1 Masson Cie, Paris, p. 462-576

Shibata, K., Haxo, F. T. (1969). Light transmission and spectral distribution through epi-and endozoic algal layers in the 
brain coral, Favia. Biol. Bull. 136: 461-468

Simpson, T. L. (1984). The cell biology of sponges. SpringerVerlag, New York, p. 1-662

Wilkinson, C. R. (1979). Nutrient translocation from symbiotic cyanobacteria to coral reef sponges. In: Levi, C., BouryEsnault, N. (eds.) Biologie des spongiaires. Colloq. Internat. C.N.R.S., Paris, p. 527-529

This article was submitted to the editor
Wilkinson, C. R. (1980). Cyanobacteria symbiotıc in marine sponges. In: Schwemmler, W., Schenk, H. E. A. (eds.) Endocytobiology, endosymbiosis and cell biology. Walter de Gruyter, New York, p. 553-563.

Yonge, C. M. (1936). Mode of life, feeding, digestion, and symbiosis with zonxanthellae in the Tridacnidae. Scient. Rep. Gt Barrier Reet Exped. 1. 283-321

Manuscript first recuived: November 11, 1993

Revised vorsion accupted: February 17, 1994 